\title{
PENGARUH JENIS TERBANG TERHADAP KONSUMSI BAHAN BAKAR PESAWAT KING AIR B200
}

\author{
The Effect of Flying Type on Fuel Consumption of King Air B200
}

AA Sagung Sri Ratih Paramitha* dan I Gede Eka Lesmana

Program Studi Teknik Mesin, Universitas Pancasila, Srengseng Sawah Jagakarsa Jakarta 12640, Indonesia

Informasi artikel

Diterima: $28 / 03 / 2020$

Direvisi : 09/05/2020

Disetujui: 26/06/2020

\begin{abstract}
Abstrak
Saat ini, pemanfaatan pesawat udara dalam moda transportasi semakin meluas, tidak hanya mengambil peran sebagai media untuk transportasi penumpang, tetapi juga digunakan sebagai media untuk melakukan uji kalibrasi terhadap navigasi pendukung keselamatan penerbangan. Uji Kalibrasi di lakukan dengan membawa alat uji di dalam pesawat yang digunakan dan melakukan prosedur untuk mengkalibrasi navigasi penerbangan termasuk manuver yang dibutuhkan. Pemanfaatan pesawat yang biasanya di gunakan untuk melakukan ferry dengan fungsi kembali ke base untuk melakukan perawatan pesawat atau membawa penumpang dari satu daerah ke daerah lain. Pesawat dengan tipe dan interval waktu penggunaan yang sama akan memiliki perbedaan konsumsi bahan bakar apabila digunakan dalam jenis pemanfaatan terbang yang berbeda. Hal ini dapat dilihat dengan melakukan uji ANOVA dan t-test menggunakan SPSS. Saat dilakukan uji dengan SPSS didapatkan hasil uji t-test menunjukkan nilai Signifikan atau Sig. sebesar 0,002 sehingga hipotesa adanya perbedaan konsumsi bahan bakar saat melakukan ferry dan kalibrasi dapat di terima. Sehingga perlu di lakukan penjadwalan terbang yang baik agar setiap pesawat dapat memasuki masa perawatan rutin yang sesuai dengan waktu yang ditentukan.
\end{abstract}

Kata Kunci: pesawat udara, konsumsi bahan bakar pesawat, jenis terbang, pengaruh jenis terbang, uji SPSS.

\begin{abstract}
Nowadays, the use of aircraft in transportation modes is increasingly widespread, not only taking the role as a medium for passenger transportation, but also being used as a medium to carry out calibration tests on navigation supporting aviation safety. Calibration test is carried out by carrying the test equipment inside the aircraft used and performing procedures to calibrate flight navigation including the maneuvering required. Utilization of aircraft that are normally used to carry ferries with the function of returning to base for aircraft maintenance or carrying passengers from one area to another. Utilization of aircraft with the same type and the same time interval will make a difference in the consumption of fuel used. This can be seen by conducting ANOVA test and t-test using SPSS. When the SPSS test was obtained the results of the t-test showed the Significant Value or Sig. 0.002 so that the hypothesis of differences in fuel consumption during ferry and calibration is acceptable. So it needs to be done a good flight scheduling so that the aircraft can be balanced into the period of routine maintenance.
\end{abstract}

Keywords: aircraft, fuel consumption, flying type, the effect of flying type, SPSS methode. 


\section{PENDAHULUAN}

Industri penerbangan telah berkembang dengan sangat cepat. Tidak hanya berperan sebagai moda transportasi untuk memindahkan penumpang dari satu daerah ke daerah lain, tetapi juga berperan penting dalam menjaga keselamatan penerbangan. Hal ini dapat dilihat dari peran pesawat udara serta personil yang berperan untuk menjaga pesawat tersebut laik udara (keadaan dimana pesawat dalam keadaan aman untuk terbang) sehingga dapat menjamin kegiatan operasional penerbangan dapat berjalan dengan baik.

Tipe pesawat yang digunakan dalam industri penerbangan juga berbagai macam dengan landasan terbang dan medan pendaratan yang dijadikan pertimbangan. Mengingat tidak setiap medan pendaratan memiliki kondisi yang sama, sehingga banyak aspek yang perlu di perhatikan dalam mengoperasikan pesawat udara. Sebuah pesawat udara dikatakan laik udara apabila telah memenuhi sertifikasi kelaikudaraan yang di keluarkan oleh Direktorat Kelaikudaraan dan Pengoperasian Pesawat Udara di Indonesia. Selain itu pesawat yang diijinkan terbang juga harus memenuhi aspek keselamatan penerbangan termasuk dokumen rilis terbang, informasi cuaca, landasan pacu dan navigasi pendukung penerbangan.

Oleh karena peran navigasi penerbangan yang semakin berkembang seiring dengan perkembangan industri penerbangan, maka sesuai dengan Peraturan Direktur Jenderal Perhubungan Udara Nomor KP 85 Tahun 2014 tentang Perubahan Atas Peraturan Direktur Jenderal Perhubungan Udara Nomor SKEP/116/VII/2010 tentang Petunjuk dan Tata Cara Penyelenggaraan Kalibrasi Fasilitas dan Prosedur Penerbangan (Advisory Circular CASR Part 171-5) Pasal 3 ayat (1) disebutkan bahwa fasilitas telekomunikasi penerbangan dan fasilitas pelayanan pendaratan visual yang di operasikan untuk pelayanan navigasi penerbangan wajib di kalibrasi secara berkala agar tetap laik operasi.

Kegiatan kalibrasi sangat diperlukan dalam upaya menjaga fasilitas navigasi penerbangan, menjamin kelaik operasian (Samsudin, 2010) alat navigasi untuk menjaga keselamatan penerbangan termasuk alat navigasi dalam membantu kegiatan take off dan landing.

Sesuai dengan Peraturan Jenderal Perhubungan Udara Nomor KP 85 Tahun 2014, kegiatan kalibrasi di lakukan untuk menjamin fasilitas navigasi penerbangan laik operasi. Kegiatan ini di lakukan secara berkala sesuai dengan masa periodisasi kalibrasi penerbangan masing-masing alat navigasi tersebut. Untuk menjamin keselamatan penerbangan dan menghindari kemungkinan kecelakaan dalam periode penerbangan, maka kalibrasi penting (Fatonah, 2014) dilakukan pada fasilitas telekomunikasi dan pelayanan pendaratan visual untuk menjamin alat pendukung penerbangan yang ada di bandar udara beroperasi sesuai standarisasi yang telah di tetapkan.

Adapun jenis terbang ferry flight adalah jenis terbang yang dilakukan ketika kembali ke hangar untuk melakukan perawatan rutin. Ferry flight dilakukan untuk kegiatan Return to Base atau RTB. Kegiatan ini umumnya di lakukan saat pesawat sudah memasuki masa perawatan berkala yang dilakukan di hangar, atau dilakukan saat pesawat dinyatakan tidak laik operasi, penundaan keberangkatan, atau selesai melaksanakan misi.

Kebutuhan terhadap pesawat yang berbeda akan berpengaruh pada konsumsi bahan bakar, jadwal perawatan berkala hingga penggantian komponen tertentu. Konsumsi bahan bakar akan berbeda (Mora dan Yusmar, 2014) apabila penggunaan pesawat berbeda walaupun dengan tipe pesawat yang sama. Penggunaan pesawat yang berbeda juga akan berpengaruh pada jadwal perawatan rutin berdasarkan jam terbang.

Oleh karena itu, diperlukan adanya analisis terhadap konsumsi bahan bakar untuk menyusun jadwal terbang pesawat yang lebih baik sehingga dapat memaksimalkan konsumsi bahan bakar dan agar jadwal perawatan rutin (Federal Aviation Administration, 2012) termasuk penggantian komponen yang diperlukan lebih teratur dan tepat waktu. Sehingga monitoring dapat dilakukan dengan lebih baik.

\section{METODOLOGI}

Langkah awal dalam memulai analisa adalah dengan pengumpulan data. Data konsumsi bahan bakar di dapatkan dari catatan AFML pesawat. AFML atau Aircraft. Flight Maintenance Logbook adalah buku wajib terbang yang ada di pesawat yang sedang beroperasi. Buku ini berisi data catatan terbang pesawat yang ditulis oleh engineer dan pilot. 
Buku ini berisi informasi konsumsi bahan bakar, keadaan terakhir pesawat dan waktu pengecekan sebelum terbang. Sedangkan sebagai pelengkap data, dilaksanakan juga kuesioner yang di ambil dari para engineer yang telah berpengalaman dalam merawat pesawat tersebut.

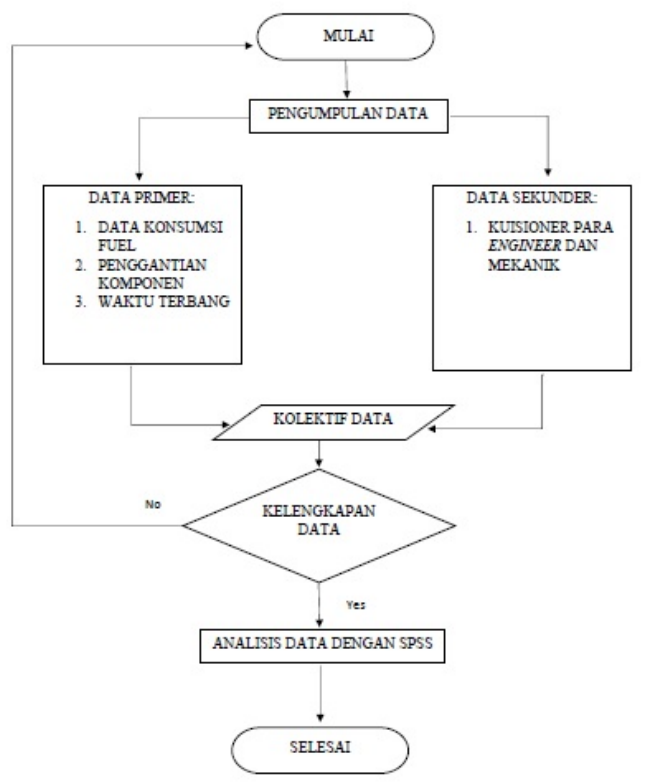

Gambar 1 Diagram Alir

Dalam diagram alir pada gambar 1, setelah pengumpulan data selesai di lakukan dan dicek kelengkapannya seperti pengisian konsumsi bahan bakar, keadaan terbang dan jam terbang dalam AFML, data akan di analisis menggunakan SPSS.

Pesawat yang digunakan adalah pesawat King Air B200 yang terdapat pada Balai Besar Kalibrasi Fasilitas Penerbangan. Data kemudian di sortir, data yang lengkap adalah data yang memenuhi pengisian logbook dengan benar dan lengkap. Data kemudian akan di sortir menjadi data baru yang akan di olah dengan aplikasi SPSS atau Statistical Package for the Social Science. Aplikasi ini adalah aplikasi statistik yang digunakan untuk melihat perbandingan dari kelompok data dengan kemungkinan signifikansi data (Sujarweni, 2015).

Aplikasi ini digunakan untuk mengolah data statitstik. Dalam pengolahan data, SPSS digunakan untuk dapat menemukan perbedaan konsumsi bahan bakar saat penerbangan kalibrasi dan ferry. Analisis di gunakan dengan metode ANOVA dan t-test karena metode ini adalah metode yang digunakan untuk melakukan perbandingan dan mencari perbedaan terhadap beberapa kelompok data.
Untuk memulai analisis dengan metode ANOVA dan t-test terlebih dahulu di lakukan uji normalitas dan homogenitas (Sujarweni, 2015). Uji Normalitas dilakukan dengan tujuan data terdistribusi dengan normal. Data yang terdistribusi normal merupakan syarat melakukan uji Anova dan t-test. Nilai ini di tunjukkan dengan nilai Sig. Nilai Sig. adalah nilai signifikansi atau nilai " $p$ value" yang artinya menunjukkan nilai kemungkinan kesalahan. Data di katakan terdistribusi normal apabila nilai Sig. lebih dari 0,05.

Setelah itu, uji homogenitas juga dilakukan sebagai syarat melaksanakan metode ANOVA dan t-test. Uji homogenitas dilakukan untuk mengetahui dua atau lebih kelompok data sampel berasal dari popupasi yang memiliki variabel sama. Hal ini di tunjukkan apabila nilai Sig lebih dari 0,05. Setelah kedua uji ini dilakukan dan dinyatakan normal dan homogen, maka uji ANOVA dan t-test dapat di lakukan.

Metode ANOVA dipilih karena merupakan metode untuk mengolah data varian sehingga dapat mengetahui perbedaan dari 2 atau lebih kelompok data. Variabel yang digunakan adalah waktu dan jenis tipe pesawat yang sama, sehingga data pembanding adalah konsumsi bahan bakar kedua jenis terbang ini dalam interval waktu tertentu sesuai dengan data AFML.

Sebelum melaksanakan olah data dengan ANOVA, dibuatkan 2 (dua) buah hipotesa positif dan negatif yaitu tidak terdapat perbedaan konsumsi bahan bakar dan terdapat perbedaan konsumsi bahan bakar. Hasil uji apabila dapat memenuhi nilai Sig di atas 0,05 maka hipotesa 1 (satu) dapat di terima namun, apabila nilai Sig di bawah 0,05 maka hipotesa 2 (dua) dapat di terima. Sehingga dari uji ini dapat di tentukan hasil dari penelitian ini.

Untuk melaksanakan olah data dengan ttest sama dengan uji Anova, dibuatkan 2 (dua) buah hipotesa postif dan negatif. Dalam uji t-test ini hasil dapat dilihat dari nilai Sig 2 tailed. Sig 2 tailed merupakan nilai signifikansi yang digunakan sebagai dasar dalam menolak atau menerima hipotesis. Nilai Sig 2 tailed berarti digunakan untuk menguji hipotesa yang tidak terarah untuk mengetahui adanya hubungan korelasi kedua data sampel. (Sujarweni, 2015) Apabila data sampel menunjukkan nilai Sig 2 tailed lebih dari 0,05 maka hipotesa bahwa tidak ada perbedaan konsumsi bahan bakar dapat di terima sedangkan apabila nilai Sig 2 tailed di bawah 0,05 maka hipotesa 2 yaitu terdapat 
perbedaan konsumsi bahan bakar kedua data sampel dapat di terima.

\section{Pengumpulan Data}

Data kuantitatif konsumsi bahan bakar pesawat jenis King Air B200 yang digunakan diambil dari 3 (tiga) registrasi berbeda dengan tipe pesawat yang sama. Berdasarkan Civil Aviation Safety Regulation atau Peraturan Perundang- undangan Penerbangan, CASR Part 45 tentang Identification and Registration Marking, Registrasi pesawat adalah alfanumerik yang diberikan pada pesawat udara sebagaimana pada plat kendaraan bermotor. Data yang di dapat dari AFML ini kemudian dimasukkan ke dalam aplikasi microsoft excel seperti tabel 1.

Data pada Tabel 1 Data Sampel Konsumsi Bahan Bakar merupakan data yang di ambil dari AFML atau Aircraft Flight Maintenance Logbook yang merupakan buku wajib terbang pesawat. Dalam buku tersebut di ambil waktu terbang dan konsumsi bahan bakar pesawat tersebut selama masing-masing penerbangan.

Tabel 1 Data Sampel Konsumsi Bahan Bakar

\begin{tabular}{|l|l|l|l|l|l|l|l|l|l|}
\hline No & $\begin{array}{l}\text { Time } \\
\text { (hour } \\
s)\end{array}$ & Category & $\begin{array}{l}\text { Ferry } \\
\text { (liter) }\end{array}$ & $\begin{array}{l}\text { Calibration } \\
\text { (iter) }\end{array}$ & $\begin{array}{l}\text { No } \\
\text { (hours } \\
\text { (nime }\end{array}$ & $\begin{array}{l}\text { Categorry } \\
\text { (iter) })\end{array}$ & $\begin{array}{l}\text { Calibration } \\
\text { (iter) }\end{array}$ \\
\hline 1 & 1,1 & 2 & 1438 & 33 & 1,2 & 1 & 1438 & \\
\hline 2 & 1,5 & 1 & 1438 & & 34 & 0,9 & 1 & 1438 & \\
\hline 3 & 2,6 & 1 & 1638 & & 35 & 3,7 & 2 & & 1838 \\
\hline 4 & 3,1 & 1 & 1400 & & 36 & 2,9 & 2 & & 1838 \\
\hline 5 & 5,35 & 1 & 1438 & & 37 & 2,9 & 2 & & 1838 \\
\hline 6 & 1,85 & 2 & & 1400 & 38 & 2,4 & 2 & & 1838 \\
\hline 7 & 0,5 & 1 & 900 & & 39 & 1,5 & 2 & & 2040 \\
\hline 8 & 0,5 & 1 & 1438 & & 40 & 3 & 1 & 2040 & \\
\hline 9 & 2,6 & 1 & 1100 & & 41 & 2 & 1 & 2040 & \\
\hline 10 & 3,9 & 1 & 2040 & & 42 & 1 & 2 & & 2040 \\
\hline 11 & 1,9 & 2 & & 1938 & 43 & 6 & 2 & & 2040 \\
\hline 12 & 0,75 & 2 & & 1838 & 44 & 5 & 2 & & 2040 \\
\hline 13 & 1,6 & 2 & & 1400 & 45 & 2 & 1 & 2040 & \\
\hline 14 & 1,15 & 2 & & 1738 & 46 & 4 & 1 & 2000 & \\
\hline 15 & 0,4 & 2 & & 1838 & 47 & 3 & 2 & & 1100 \\
\hline 16 & 2,5 & 2 & & 2038 & 48 & 2 & 1 & 1100 & \\
\hline 17 & 1,3 & 1 & 1200 & & 49 & 1,5 & 1 & 400 & \\
\hline 18 & 2,7 & 2 & & 1200 & 50 & 4 & 2 & & 1838 \\
\hline 19 & 6,65 & 1 & 1938 & & 51 & 1 & 2 & & 2040 \\
\hline 20 & 2,7 & 2 & & 2040 & 52 & 1,5 & 2 & & 2000 \\
\hline 21 & 2,8 & 2 & & 1700 & 53 & 4 & 1 & 2038 & \\
\hline 22 & 4,3 & 2 & & 1938 & 54 & 4 & 2 & & 2040 \\
\hline 23 & 1,5 & 2 & & 2040 & 55 & 3 & 2 & & 2040 \\
\hline 24 & 4,4 & 2 & & 2200 & 56 & 2 & 1 & 1838 & \\
\hline 25 & 6,3 & 2 & & 1838 & 57 & 1,5 & 1 & 1438 & \\
\hline 26 & 3,5 & 1 & 1738 & & 58 & 2,5 & 1 & 2040 & \\
\hline 27 & 3,4 & 1 & 2038 & & 59 & 3 & 1 & 2040 & \\
\hline 28 & 7 & 2 & & 2040 & 60 & 2,5 & 2 & & 2040 \\
\hline 29 & 2 & 2 & & 1838 & 61 & 7 & 1 & 2040 & \\
\hline 30 & 1,6 & 2 & & 1438 & 62 & 2,5 & 2 & & 2040 \\
\hline 31 & 1,1 & 1 & 1200 & & 63 & 1 & 2 & & 1600 \\
\hline 32 & 0,5 & 1 & 1450 & & 64 & 6 & 1 & 1638 & \\
\hline & & & & & & & \\
\hline
\end{tabular}

Tabel 1 Data Sampel Konsumsi Bahan Bakar (lanjutan)

\begin{tabular}{|c|c|c|c|c|c|c|c|c|c|}
\hline No & \begin{tabular}{|l|} 
Time \\
(hour \\
s)
\end{tabular} & Category & $\begin{array}{l}\text { Ferry } \\
\text { (iter) }\end{array}$ & \begin{tabular}{|l|} 
Calibration \\
(liter)
\end{tabular} & No & \begin{tabular}{|l|} 
Time \\
(hours \\
,
\end{tabular} & Category & \begin{tabular}{|l} 
Ferry \\
(iter)
\end{tabular} & $\begin{array}{l}\text { Calibration } \\
\text { (liter) }\end{array}$ \\
\hline 65 & 1 & 1 & 1450 & & 108 & 3,7 & 1 & 2040 & \\
\hline 66 & 1,5 & 1 & 2040 & & 109 & 2,5 & 1 & 1838 & \\
\hline 67 & 1 & 1 & 2040 & & 110 & 3,8 & 1 & 2040 & \\
\hline 68 & 4 & 2 & & 1838 & 111 & 3 & 2 & & 1838 \\
\hline 69 & 3 & 2 & & 1838 & 112 & 1 & 2 & & 2000 \\
\hline 70 & 3 & 2 & & 1838 & 113 & 5,2 & 2 & & 2238 \\
\hline 71 & 2,5 & 2 & & 1838 & 114 & 3 & 2 & & 2040 \\
\hline 72 & 5,8 & 1 & 2040 & & 115 & 3,5 & 2 & & 2040 \\
\hline 73 & 5,2 & 1 & 2040 & & 116 & 2,5 & 2 & & 1438 \\
\hline 74 & 3,1 & 1 & 2040 & & 117 & 1,5 & 2 & & 2040 \\
\hline 75 & 5,5 & 1 & 2040 & & 118 & 1,6 & 2 & & 2040 \\
\hline 76 & 5,3 & 1 & 2040 & & 119 & 1,8 & 2 & & 2040 \\
\hline 77 & 5,3 & 1 & 2040 & & 120 & 2,7 & 2 & & 1638 \\
\hline 78 & 3 & 1 & 1838 & & 121 & 1 & 2 & & 1438 \\
\hline 79 & 3 & 1 & 1000 & & 122 & 2 & 2 & & 2040 \\
\hline 80 & 3 & 1 & 2040 & & 123 & 1 & 2 & & 2040 \\
\hline 81 & 4,1 & 1 & 2040 & & 124 & 3 & 2 & & 1638 \\
\hline 82 & 2,5 & 1 & 2038 & & 125 & 1 & 2 & & \begin{tabular}{|l|}
1438 \\
\end{tabular} \\
\hline 83 & 3,5 & 2 & & 2038 & 126 & 7,7 & 1 & 1438 & \\
\hline 84 & 4,75 & 2 & & 2040 & 127 & 6 & 2 & & 3676 \\
\hline 85 & 2,5 & 2 & & 1838 & 128 & 5,5 & 2 & & 1838 \\
\hline 86 & 2 & 1 & 1838 & & 129 & 5 & 2 & & 1638 \\
\hline 87 & 1,25 & 2 & & 1838 & 130 & 6,4 & 2 & & 1638 \\
\hline 88 & 5 & 2 & & 2238 & 131 & 0,8 & 2 & & 1438 \\
\hline 89 & 2,5 & 2 & & 1788 & 132 & 7 & 2 & & 2040 \\
\hline 90 & 2 & 1 & 1788 & & 133 & 5 & 2 & & 2040 \\
\hline 91 & 2,5 & 2 & & 2040 & 134 & 3,9 & 2 & & 1638 \\
\hline 92 & 1,5 & 2 & & 2040 & 135 & 1 & 2 & & 1438 \\
\hline 93 & 1,5 & 2 & & 2040 & 136 & 1 & 2 & & 1638 \\
\hline 94 & 3 & 2 & & 2038 & 137 & 2 & 2 & & 1838 \\
\hline 95 & 0,5 & 1 & 1638 & & 138 & 1,8 & 2 & & 1838 \\
\hline 96 & 3,3 & 1 & 1838 & & 139 & 4 & 2 & & 1838 \\
\hline 97 & 1,9 & 1 & 1838 & & 140 & 2,7 & 2 & & 1838 \\
\hline 98 & 2,5 & 1 & 1838 & & 141 & 3,5 & 2 & & 1838 \\
\hline 99 & 1,7 & 2 & & 2000 & 142 & 4,7 & 2 & & 1838 \\
\hline 100 & 3,2 & 2 & & 2040 & 143 & 2 & 2 & & 1438 \\
\hline 101 & 3,1 & 2 & & 2040 & 144 & 3 & 2 & & 1838 \\
\hline 102 & 0,4 & 2 & & 2040 & 145 & 2,3 & 2 & & 1838 \\
\hline 103 & 3,3 & 1 & 1738 & & 146 & 1 & 2 & & 1838 \\
\hline 104 & 1,5 & 1 & 1638 & & 147 & 3,6 & 2 & & 1838 \\
\hline 105 & 1,5 & 1 & 1638 & & 148 & 1,7 & 2 & & 2040 \\
\hline 106 & 3,7 & 1 & 1838 & & 149 & 5,5 & 2 & & 1838 \\
\hline 107 & 3,1 & 1 & 1838 & & 150 & 1 & 2 & & 1638 \\
\hline
\end{tabular}

Data yang di ambil pada AFML di bedakan menjadi bahan bakar yang di habiskan saat penerbangan kalibrasi dan ferry dengan masing-masing waktu tempuh untuk kemudian di sortir yang memiliki interval waktu yang sama, sedangkan warna menunjukkan registrasi ketiga pesawat dengan tipe yang sama.

\section{Membuat Time Frame}

Data yang sudah didapatkan pada tabel 1 adalah data sampel konsumsi bahan bakar akan di kelompokkan menurut time frame (seperti pada tabel 2-9 Time Frame). Time frame dibuat berdasarkan skala waktu antara penerbangan kalibrasi dan ferry. Berdasarkan waktu yang di dapatkan pada AFML, time frame dapat dibuat ke dalam 8 skala setiap 1 (satu) jam yaitu time frame 0,1 hingga 1 jam, 1,1 hingga 2 jam begitu 
seterusnya hingga waktu maksimal pada data sampel. Hal ini bertujuan agar klasifikasi data lebih spesifik dilakukan.

Pengelompokkan data berdasarkan time frame dilakukan dengan tujuan memetakan data yang didapat agar memiliki perbandingan jumlah yang sama antara kalibrasi dan ferry. Data akan di kelompokkan menjadi 8 time frame karena adanya pendataan terhadap AFML yang menunjukkan waktu maksimal dalam data sampel adalah 7,3 sedangkan waktu minimal dalam data adalah 0,4.

Tabel 2 Time Frame 1

\begin{tabular}{|l|l|l|l|l|}
\hline No & Waktu (hours) & Kalibrasi (liter) & Waktu (hours) & Ferry (liter) \\
\hline 1 & $0,75 h$ & $1838 l$ & $0,5 h$ & $1450 l$ \\
\hline 2 & $0,4 h$ & $1838 l$ & $0,9 h$ & $1438 l$ \\
\hline 3 & $1 h$ & $2040 l$ & $1 h$ & $1450 l$ \\
\hline 4 & $1 h$ & $1600 l$ & $1 h$ & $2040 l$ \\
\hline 5 & $0,4 h$ & $2040 l$ & $0,5 h$ & $1638 l$ \\
\hline 6 & $1 h$ & $2000 l$ & $0,5 h$ & $1200 l$ \\
\hline 7 & $1 h$ & $1438 l$ & $1 h$ & $1200 l$ \\
\hline 8 & $1 h$ & $2040 l$ & $0,5 h$ & $1100 l$ \\
\hline 9 & $1 h$ & $1438 l$ & $0,9 h$ & $1638 l$ \\
\hline 10 & $1 h$ & $1638 l$ & $0,8 h$ & $1838 l$ \\
\hline 11 & $1 h$ & $1438 l$ & $0,5 h$ & $900 l$ \\
\hline
\end{tabular}

Tabel 3 Time Frame 2

\begin{tabular}{|l|l|l|l|l|}
\hline No & Waktu (hours) & Kalibrasi (liter) & Waktu (hours) & Ferry (liter) \\
\hline 1 & $1,1 h$ & $1438 l$ & $1,5 h$ & $1438 l$ \\
\hline 2 & $1,85 h$ & $1400 l$ & $1,3 h$ & $1200 l$ \\
\hline 3 & $1,9 h$ & $1938 l$ & $1,1 h$ & $1200 l$ \\
\hline 4 & $1,6 h$ & $1400 l$ & $1,2 h$ & $1438 l$ \\
\hline 5 & $1,15 h$ & $1738 l$ & $2 h$ & $2040 l$ \\
\hline 6 & $1,5 h$ & $2040 l$ & $1,5 h$ & $400 l$ \\
\hline 7 & $1,6 h$ & $1438 l$ & $2 h$ & $1838 l$ \\
\hline 8 & $1,5 h$ & $2040 l$ & $1,5 h$ & $1438 l$ \\
\hline 9 & $1 h$ & $2040 l$ & $2 h$ & $2040 l$ \\
\hline 10 & $1,5 h$ & $2000 l$ & $2 h$ & $1100 l$ \\
\hline 11 & $1,25 h$ & $1838 l$ & $1,5 h$ & $2040 l$ \\
\hline 12 & $1,5 h$ & $2040 l$ & $2 h$ & $1838 l$ \\
\hline 13 & $1,5 h$ & $2040 l$ & $2 h$ & $1788 l$ \\
\hline 14 & $1,7 h$ & $2000 l$ & $1,9 h$ & $1838 l$ \\
\hline 15 & $1,5 h$ & $2040 l$ & $1,5 h$ & $1638 l$ \\
\hline 16 & $1,6 h$ & $2040 l$ & $1,5 h$ & $1638 l$ \\
\hline 17 & $1,8 h$ & $2040 l$ & $2 h$ & $1550 l$ \\
\hline 18 & $2 h$ & $2040 l$ & $2 h$ & $1600 l$ \\
\hline 19 & $1,7 h$ & $1838 l$ & $1,5 h$ & $1200 l$ \\
\hline 20 & $2 h$ & $1838 l$ & $2 h$ & $1438 l$ \\
\hline 21 & $1,3 h$ & $1438 l$ & $1,6 h$ & $1400 l$ \\
\hline 22 & $1,6 h$ & $1638 l$ & $2 h$ & $1438 l$ \\
\hline Time Frame 2 (dengan skala waktu 1.1 - 2) & & \\
\hline
\end{tabular}

Tabel 2 memperlihatkan data time frame 1 , dengan skala 0.1 - 1.0 jam, sedangkan pada tabel 3 menampilkan data time frame 2 dengan skala waktu 1.1 - 2 jam.
Tabel 4 Time Frame 3

\begin{tabular}{|c|c|c|c|c|}
\hline No & Waktu (hours) & Kalibrasi (liter) & Waktu (hours) & Ferry (liter) \\
\hline 1 & $2,5 h$ & $2038 l$ & $2,6 h$ & $1638 l$ \\
\hline 2 & $2,7 h$ & $1200 l$ & $2,5 h$ & $2040 l$ \\
\hline 3 & $2,7 h$ & $2040 l$ & $3 h$ & $2040 l$ \\
\hline 4 & $2,8 h$ & $1700 l$ & $3 h$ & $2040 l$ \\
\hline 5 & $2 h$ & $1838 l$ & $3 h$ & $1838 l$ \\
\hline 6 & $2,9 h$ & $1838 l$ & $3 h$ & $1000 l$ \\
\hline 7 & $2,9 h$ & $1838 l$ & $3 h$ & $2040 l$ \\
\hline 8 & $2,4 h$ & $1838 l$ & $2,5 h$ & $2038 l$ \\
\hline 9 & $3 h$ & $1100 l$ & $2,5 h$ & $1838 l$ \\
\hline 10 & $3 h$ & $2040 l$ & $2,5 h$ & $1838 l$ \\
\hline 11 & $2,5 h$ & $2040 l$ & $3 h$ & $1438 l$ \\
\hline 12 & $2,5 h$ & $2040 l$ & $2,7 h$ & $1600 l$ \\
\hline 13 & $3 h$ & $1838 l$ & $3 h$ & $1600 l$ \\
\hline 14 & $3 h$ & $1838 l$ & $2,7 h$ & $1600 l$ \\
\hline 15 & $2,5 h$ & $1838 l$ & $2,9 h$ & $1838 l$ \\
\hline 16 & $2,5 h$ & $1838 l$ & $2,5 h$ & $1800 l$ \\
\hline 17 & $2,5 h$ & $1788 l$ & $2,7 h$ & $2040 l$ \\
\hline 18 & $2,5 h$ & $2040 l$ & $2,3 h$ & $1838 l$ \\
\hline 19 & $3 h$ & $2038 l$ & $2,2 h$ & $1538 l$ \\
\hline 20 & $3 h$ & $1838 l$ & $3 h$ & $2040 l$ \\
\hline 21 & $3 h$ & $2040 l$ & $2,7 h$ & $1838 l$ \\
\hline 22 & $2,5 h$ & $1438 l$ & $2,5 h$ & $1838 l$ \\
\hline 23 & $2,7 h$ & $1638 l$ & $2,4 h$ & $1638 l$ \\
\hline 24 & $3 h$ & $1638 l$ & $2,8 h$ & $1638 l$ \\
\hline 25 & $2,3 h$ & $1838 l$ & $2,9 h$ & $1638 l$ \\
\hline 26 & $3 h$ & $1638 l$ & $2,5 h$ & $1100 l$ \\
\hline 27 & $2,5 h$ & $1438 l$ & $3 h$ & $1438 l$ \\
\hline 28 & $3 h$ & $1838 l$ & $3 h$ & $800 l$ \\
\hline 29 & $2,5 h$ & $1438 l$ & $3 h$ & $1738 l$ \\
\hline
\end{tabular}

Tabel 5 Time Frame 4

\begin{tabular}{|l|l|l|l|l|}
\hline No & Waktu (hours) & Kalibrasi (liter) & Waktu (hours) & Ferry (iter) \\
\hline 1 & $3,7 h$ & $1838 l$ & $3,1 h$ & $1400 l$ \\
\hline 2 & $4 h$ & $1838 l$ & $3,9 h$ & $2040 l$ \\
\hline 3 & $4 h$ & $2040 l$ & $3,5 h$ & $1738 l$ \\
\hline 4 & $4 h$ & $1838 l$ & $3,4 h$ & $2038 l$ \\
\hline 5 & $3,1 h$ & $2040 l$ & $4 h$ & $2000 l$ \\
\hline 6 & $3,5 h$ & $2038 l$ & $4 h$ & $2038 l$ \\
\hline 7 & $3,2 h$ & $2040 l$ & $3,3 h$ & $1838 l$ \\
\hline 8 & $3,1 h$ & $2040 l$ & $3,3 h$ & $1738 l$ \\
\hline 9 & $3,5 h$ & $2040 l$ & $3,7 h$ & $1838 l$ \\
\hline 10 & $3,5 h$ & $1838 l$ & $3,1 h$ & $1838 l$ \\
\hline 11 & $3,5 h$ & $1438 l$ & $3,7 h$ & $2040 l$ \\
\hline 12 & $3,7 h$ & $1438 l$ & $3,8 h$ & $2040 l$ \\
\hline 13 & $3,5 h$ & $2040 l$ & $3,3 h$ & $1100 l$ \\
\hline \multicolumn{2}{|l|}{ Time frame 4 (dengan skala $3.1-4)$} & & \\
\hline
\end{tabular}

Tabel 6 Time Frame 5

\begin{tabular}{|l|l|l|l|l|}
\hline No & Waktu (hours) & Kalibrasi (liter) & Waktu (hours) & Ferry (liter) \\
\hline 1 & $4,3 h$ & $1938 l$ & $4,1 h$ & $2040 l$ \\
\hline 2 & $4,4 h$ & $2200 l$ & $4,3 h$ & $1438 l$ \\
\hline 3 & $5 h$ & $2040 l$ & $5 h$ & $2040 l$ \\
\hline 4 & $4,75 h$ & $2040 l$ & $5 h$ & $1638 l$ \\
\hline 5 & $5 h$ & $2238 l$ & $4,6 h$ & $1638 l$ \\
\hline
\end{tabular}

Time Frame 5 (dengan skala 4.1 -5) 
Tabel 3 memperlihatkan data time frame 3 , dengan skala 2.1 - 3 jam, sedangkan pada tabel 5 menampilkan data time frame 4 dengan skala waktu 3.1 - 4 jam. Tabel 6 menyajikan data time frame 5 dengan skala waktu 4.1 - 5 jam. Sedangkan tabel 7 menampilkan data frame 6 dengan skala 5.1 - 6 jam.

Tabel 7 Time Frame 6

\begin{tabular}{|l|l|l|l|l|}
\hline No & Waktu (hours) & Kalibrasi (liter) & Waktu (hours) & Ferry (liter) \\
\hline 1 & $6 h$ & $2040 l$ & $5,35 h$ & $1438 l$ \\
\hline 2 & $5,5 h$ & $1838 l$ & $6 h$ & $1638 l$ \\
\hline 3 & $6 h$ & $3676 l$ & $5,8 h$ & $2040 l$ \\
\hline 4 & $5,2 h$ & $2238 l$ & $5,2 h$ & $2040 l$ \\
\hline 5 & $5,4 h$ & $2040 l$ & $5,5 h$ & $2040 l$ \\
\hline 6 & $5,9 h$ & $2038 l$ & $5,3 h$ & $2040 l$ \\
\hline 7 & $5,2 h$ & $4080 l$ & $5,3 h$ & $2040 l$ \\
\hline 8 & $5,3 h$ & $3676 l$ & $6 h$ & $1838 l$ \\
\hline
\end{tabular}

Tabel 8 Time Frame 7

\begin{tabular}{|l|l|l|l|l|}
\hline No & Waktu (hours) & Kalibrasi (liter) & Waktu (hours) & Ferry (liter) \\
\hline 1 & $6,3 h$ & $1838 l$ & $6,65 h$ & $1938 l$ \\
\hline 2 & $7 h$ & $2040 l$ & $6,1 h$ & $2000 l$ \\
\hline
\end{tabular}

Tabel 9 Time Frame 8

\begin{tabular}{|l|l|l|l|l|}
\hline No & Waktu (hours) & Kalibrasi (liter) & Waktu (hours) & Ferry (liter) \\
\hline 1 & $7,2 h$ & $1838 l$ & $7,7 h$ & $1438 l$ \\
\hline 2 & $7,3 h$ & $1938 l$ & $7,8 h$ & $1638 l$ \\
\hline
\end{tabular}

Time frame 8 (dengan skala 7.1 -8)

Tabel 8 dan 9 memperlihatkan data time frame skala 6.1 - 7 jam untuk time frame 7 dan skala 7.1 - 8 jam pada time frame 8 .

\section{Membuat Irisan Himpunan}

Irisan himpunan dibuat berdasarkan data time frame pada tabel 2 hingga tabel 9. Irisan himpunan dibuat untuk mengerucutkan data spesifik terhadap kesamaan data waktu.

Irisan himpunan di buat dengan memasukkan data waktu penerbangan pada tabel 2 hingga tabel 9 time frame berdasarkan skala yang telah di buat. Hal ini bertujuan untuk menemukan data tunggal dengan membandingkan dua kelompok data pada waktu yang sama seperti pada gambar 2 dan 3.

Data himpunan 1 dan 2 di buat mengikuti data pada tabel 2 hinggal tabel 9 data time frame untuk mendapatkan data yang lebih spesifik. Maka dengan membuat himpunan, dapat diketahui terdapat irisan waktu yang menunjukkan kesamaan variable waktu perbandingan pada setiap skala, seperti pada Gambar 2 himpunan 1 terdapat kesamaan pada data pada waktu 1 jam, oleh karena itu dapat ditarik rata-rata data kalibrasi dan ferry untuk mewakili data 1 jam dan seterusnya.

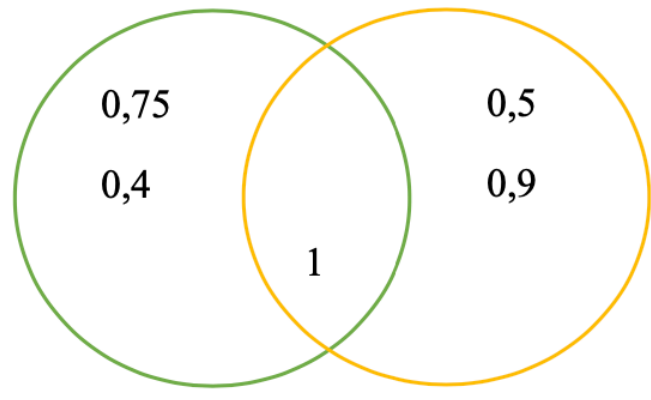

\section{K1 $\cap$ F1}

Gambar 2 Himpunan 1

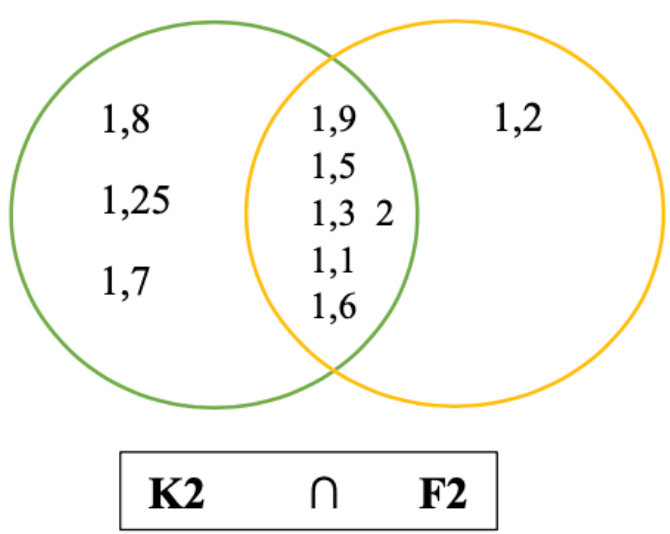

Gambar 3 Himpunan 2

Setelah itu pada interval waktu yang sama di buat kelompok perwakilan data konsumsi bahan bakar antara penerbangan ferry dan kalibrasi seperti pada tabel 10 dan 11. Pada Tabel 10 dan tabel 11 merupakan Perwakilan Data Hasil Himpunan, setelah mengelompokan data berdasarkan kesamaan waktu, konsumsi bahan bakar di ambil dengan rata-rata setiap interval waktu. Sehingga didapat data untuk selanjutnya di gunakan sebagai data input ke dalam SPSS.

Tabel 10 Perwakilan Data Hasil Himpunan 1

\begin{tabular}{|l|l|l|l|}
\hline $\begin{array}{c}\text { Waktu } \\
\text { (jam) }\end{array}$ & Flight & Data (liter) & Mean (liter) \\
\hline \multirow{2}{*}{1 jam } & Kalibrasi & $\begin{array}{l}2040,1600,2000,1438,2040,1438, \\
1638,1438\end{array}$ & $=1704$ \\
\cline { 2 - 4 } & Ferry & $1450,2040,1200$ & $=1563,3$ \\
\hline
\end{tabular}


Tabel 11 Perwakilan Data Hasil Himpunan 2

\begin{tabular}{|c|c|c|c|}
\hline $\begin{array}{l}\text { Waktu } \\
\text { (jam) }\end{array}$ & Flight & Data (liter) & Mean (liter) \\
\hline \multirow{2}{*}{$\begin{array}{l}1.1 \\
\text { jam }\end{array}$} & Kalibrasi & 1438 & $=1438$ \\
\hline & Ferry & 1600 & $=1600$ \\
\hline \multirow{2}{*}{$\begin{array}{l}1.3 \\
\text { jam }\end{array}$} & Kalibrasi & 1438 & $=1438$ \\
\hline & Ferry & 1200 & $=1200$ \\
\hline \multirow{2}{*}{$\begin{array}{l}1.5 \\
\text { jam }\end{array}$} & Kalibrasi & $2040,2040,2000,2040,2040,2040$ & $=2033,3$ \\
\hline & Ferry & $1438,400,1438,2040,1638,1638,1200$ & $=1398,8$ \\
\hline \multirow{2}{*}{$\begin{array}{l}1.6 \\
\text { jam }\end{array}$} & Kalibrasi & $1400,1438,2040,1638$ & $=1629$ \\
\hline & Ferry & 1838 & $=1838$ \\
\hline \multirow{2}{*}{$\begin{array}{l}1.9 \\
\text { jam }\end{array}$} & Kalibrasi & 1938 & $=1938$ \\
\hline & Ferry & 1800 & $=1800$ \\
\hline \multirow[b]{2}{*}{2 jam } & Kalibrasi & $2040,1838,1550$ & $=1809,3$ \\
\hline & Ferry & $\begin{array}{l}2040,1838,2040,1100,1838,1788, \\
1550,1600,1438,1438\end{array}$ & $=1667$ \\
\hline
\end{tabular}

\section{Data input SPSS}

Data pada tabel 12 Data input SPSS diatas merupakan hasil pengolahan data yang dilakukan sebelumnya. Data ini berisi waktu dan konsumsi bahan bakar yang akan di gunakan sebagai data input yang akan di olah dengan SPSS.

\section{Uji Normalitas}

Sebelum melakukan analisis dengan ANOVA pada SPSS, perlu dilakukan uji normalitas dengan tujuan memastikan data terdistribusi dengan normal. Karena apabila data tidak dinyatakan terdistribusi dengan normal, maka uji Anova dan t-test tidak dapat dilakukan (Zulaichah, 2014). Syarat fungsi Uji Normalitas adalah:

1. Apabila Signifikansi (Sig.) lebih besar dari 0,05 maka data penelitian berdistribusi normal

2. Apabila signifikansi (Sig.) lebih kecil dari 0,05 maka data penelitian tidak berdistribusi normal.

Dalam hal ini uji normalitas dilakukan terhadap sampel $X$ dan Y. Dimana $X$ adalah konsumsi bahan bakar pada saat kalibrasi dan $Y$ adalah konsumsi bahan bakar pada saat ferry. Adapun uji normalitas pengaruh sampel $X$ terhadap $Y$ adalah seperti pada gambar 4.

Dari hasil uji normalitas pada gambar 4 diketahui hasil nilai adalah Sig. 0,998 $>0,05$ sehingga dapat disimpulkan bahwa data terdistribusi dengan normal. Dengan demikian, data dapat digunakan untuk melakukan uji SPSS berikutnya.
Tabel 12 Data Input SPSS

\begin{tabular}{|c|c|c|c|}
\hline No & $\begin{array}{l}\text { Time } \\
\text { (hours) }\end{array}$ & $\begin{array}{l}\text { Calibration } \\
\text { (liter) }\end{array}$ & $\begin{array}{l}\text { Ferry } \\
\text { (liter) }\end{array}$ \\
\hline 1 & 1 & 1704 & 1563,3 \\
\hline 2 & 1,1 & 1438 & 1200 \\
\hline 3 & 1,3 & 1438 & 1200 \\
\hline 4 & 1,5 & 2033,3 & 1398,8 \\
\hline 5 & 1,6 & 1629 & 1400 \\
\hline 6 & 1,9 & 1938 & 1838 \\
\hline 7 & 2 & 1809,3 & 1667 \\
\hline 8 & 2,3 & 1838 & 1838 \\
\hline 9 & 2,4 & 1838 & 1638 \\
\hline 10 & 2,5 & 1793,6 & 1784,5 \\
\hline 11 & 2,7 & 1626 & 1769,5 \\
\hline 12 & 2,8 & 1700 & 1638 \\
\hline 13 & 2,9 & 1838 & 1738 \\
\hline 14 & 3 & 1784,6 & 1637,4 \\
\hline 15 & 3,1 & 2040 & 1619 \\
\hline 16 & 3,5 & 1878,8 & 1738 \\
\hline 17 & 3,7 & 1638 & 1939 \\
\hline 18 & 4 & 1905,3 & 2019 \\
\hline 19 & 4,3 & 1938 & 1438 \\
\hline 20 & 5 & 2139 & 1839 \\
\hline 21 & 5,2 & 3159 & 2040 \\
\hline 22 & 5,3 & 3676 & 2040 \\
\hline 23 & 5,5 & 1838 & 2040 \\
\hline 24 & 6 & 2858 & 1738 \\
\hline
\end{tabular}

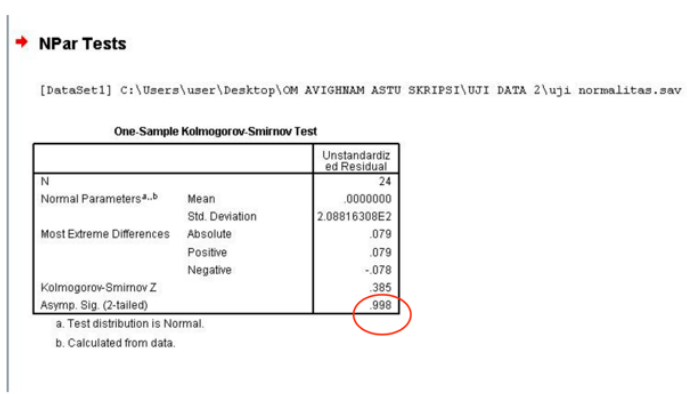

Gambar 4 Uji Normalitas 


\section{Uji Homogenitas}

Uji homogenitas juga merupakan salah satu syarat setelah melaksanakan uji normalitas yang digunakan sebagai penentu data homogen yang akan di uji dengan uji ANOVA maupun t-test (Sujarweni, 2015) . Uji ini memiliki tujuan untuk mengetahui apakah variasi dari beberapa kelompok data memiliki varian yang sama atau tidak. Syarat hasil uji ini adalah

1. Jika nilai signifikansi atau Sig. $<0,05$ maka varians kedua kelompok tidak sama (tidak homogen)

2. Jika nilai signifikasnsi atau Sig. $>0,05$ maka varians kedua kelompok sama (homogen)

Uji dilakukan dengan memasukkan data konsumsi bahan bakar kedua kelompok dengan 2 (dua) buah label pada value yaitu 1 untuk kalibrasi dan 2 untuk ferry. Adapun uji dilakukan dengan aplikasi analyze dan compare means one way anova dimana data konsumsi bahan bakar sebagai dependent list dengan tipe penerbangan sebagai faktor yang dibandingkan maka di dapatkan hasil seperti pada gambar 5 .

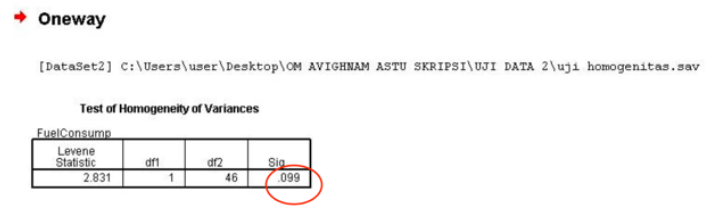

Gambar 5 Uji Homogenitas

Dari gambar 5, didapatkan nilai Sig 0,099 $>0,05$ maka data diatas memenuhi syarat pengujian data ANOVA dan t-test dimana data tersebut dinyatakan homogen.

\section{Uji ANOVA}

Setelah melakukan uji homogen dan uji normalitas, data yang dinyatakan normal dan homogen dapat di lakukan uji ANOVA. Uji anova dilakukan dengan memasukkan waktu dan konsumsi bahan bakar. Dalam uji ini sebelumnya terdapat 2 hipotesis yang dapat dibuktikan dengan hasil uji yaitu

Ho: Tidak terdapat perbedaan antara konsumsi bahan bakar saat kalibrasi dengan ferry

Ha: Terdapat perbedaan antara konsumsi bahan bakar saat kalibrasi dengan ferry

Dengan memperhatikan nilai Sig. Apabila lebih besar dari (>) 0,05 maka hipotesis Ho dapat diterima, namun sebaliknya apabila nilai Sig. kurang dari (<) 0,05 hipotesis Ho ditolak dan Ha diterima. Uji dilakukan dengan memasukkan data konsumsi bahanbakar dan waktu sebagai dependent list dengan perlakuan terbang kalibrasi dan ferry sebagai factor yang dibandingkan. Adapun hasil uji ANOVA adalah seperti diperlihatkan pada gambar 6 .

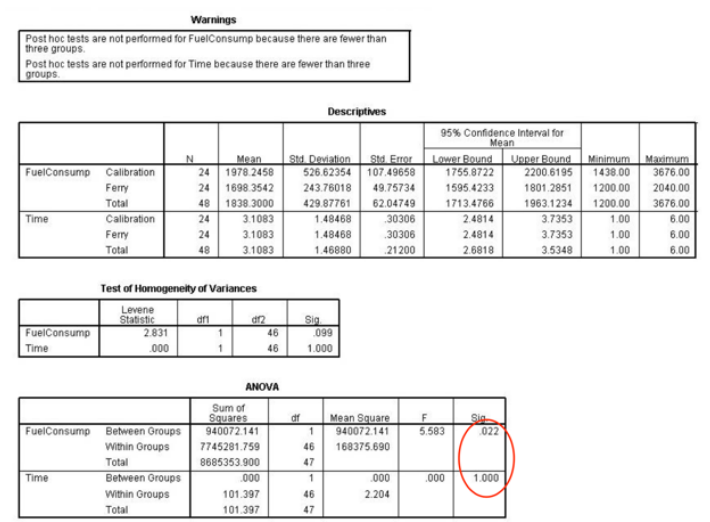

Gambar 6 Uji ANOVA

Dari hasil data gambar 6, dapat dilihat nilai Sig. Waktu terbang adalah 1,000 dengan homogenity 1,000 dimana nilai tersebut lebih besar dari 0,05 maka hipotesis Ho dapat di terima oleh uji ANOVA terhadap waktu. Namun untuk konsumsi bahan bakar, hasil Sig. menunjukkan 0,022 dimana nilai tersebut kurang dari 0,05 sehingga hipotesis Ho ditolak dan hipotesis Ha dapat diterima untuk analisis konsumsi bahan bakar. Maka terdapat perbedaan data antara kalibrasi dan ferry yang dapat dijadikan pertimbangan dalam konsumsi bahan bakar.

Dari data gambar 6, dengan jumlah banyaknya data antar kedua kelompok sama, dapat dilihat terdapat perbedaan yang cukup signifikan yang sudah dibuktikan dengan nilai signifikansi. Untuk mengetahui nilai perbedaan signifikansi konsumsi bahan bakar tersebut akan dilakukan dengan uji sampel ttest.

\section{Uji t-test}

Uji t-test ini dilakukan pada dua kelompok data dengan tujuan membandingkan dua kelompok data yang tidak berpasangan. Sebelum dilakukan uji ttest dibuat hipotesis penelitian komparatif sebagai berikut

Ho : Tidak terdapat perbedaan rata- rata konsumsi bahan bakar antara penerbangan kalibrasi dan ferry 
$\mathrm{Ha}$ : Ada perbedaan rata-rata konsumsi bahan bakar antara penerbangan kalibrasi dengan ferry.

Sama halnya dengan melakukan uji ANOVA, data yang dimasukkan adalah konsumsi bahan bakar dan tipe penerbangan dengan 2 (dua) value yaitu 1 untuk kalibrasi dan 2 untuk ferry. Uji sampel t-test dilakukan dengan menu analyze dan independent samples $t$-test dengan konsumsi bahan bakar dimasukkan dalam test variable sedangkan flights dimasukkan dalam grouping variable.

Dasar pengambilan keputusan uji t- test ini apabila

1. Jika nilai Sig (2-tailed) $>0,05$ maka Ho diterima dan $\mathrm{Ha}$ ditolak, yang berati tidak ada perbedaan antara konsumsi bahan bakar penerbangan ferry dan kalibrasi

2. Jika nilai Sig (2-tailed) $<0,05$ maka Ho ditolak dan Ha diterima, yang berarti ada perbedaan rata-rata konsumsi bahan bakar penerbangan ferry dan kalibrasi.

Adapun output uji sampel t-test adalah seperti pada gambar 7. Dari hasil data uji sampel t-test dapat dilihat nilai Sig (2-tailed) adalah 0,022 atau kurang dari 0,05 sehingga dapat ditarik keputusan Ho ditolak dan $\mathrm{Ha}$ diterima sehingga ada perbedaan antara konsumsi bahan bakar kalibrasi dan ferry dengan waktu tempuh yang sama. Interval perbedaan kedua kelompok data dapat dilihat pula dari nilai lower dan upper kedua kelompok data dan nilai mean pada group statistic.

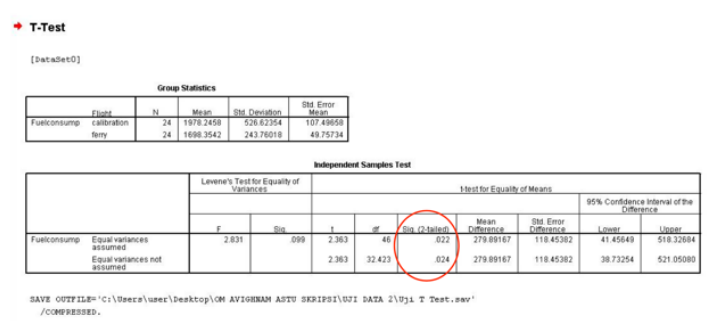

Gambar 7 Uji t-test

\section{HASIL DAN PEMBAHASAN}

Berdasarkan uji data yang telah di lakukan dengan SPSS, uji homogenitas dan normalitas yang dilakukan menunjukkan bahwa data terdistribusi dengan normal dan homogen sehingga uji ANOVA dan t-test dapat dilakukan. Setelah dilakukan uji ANOVA, didapatkan hasil nilai Sig. Waktu terbang adalah 1,000 dengan homogenity
1,000 dimana nilai tersebut lebih besar dari 0,05 sehingga hipotesis Ho dapat di terima yaitu tidak adanya perbedaan pada perbandingan waktu.

Namun untuk konsumsi bahan bakar, hasil Sig. menunjukkan 0,022 dimana nilai tersebut kurang dari 0,05 sehingga hipotesis Ho ditolak dan hipotesis Ha dapat diterima sehingga terdapat perbedaan konsumsi bahan bakar untuk analisis konsumsi bahan bakar. Maka terdapat perbedaan data antara kalibrasi dan ferry yang dapat dijadikan pertimbangan dalam konsumsi bahan bakar.

Hasil serupa juga di dapatkan saat uji ttest dari hasil data uji sampel t-test dapat dilihat nilai Sig (2-tailed) adalah 0,022 atau kurang dari 0,05 sehingga dapat ditarik keputusan Ho ditolak dan $\mathrm{Ha}$ diterima. Dimana Ha menyatakan ada perbedaan ratarata konsumsi bahan bakar antara penerbangan kalibrasi dengan ferry.

Berdasarkan hasil yang telah diuji, maka hasil yang di dapatkan adalah adanya perbedaan konsumsi bahan bakar pesawat King Air B200 pada saat melakukan kalibrasi dan ferry dimana kalibrasi menghabiskan lebih banyak bahan bakar dibanding ferry dalam interval waktu yang sama dan jenis pesawat udara yang sama. Data tersebut juga dapat dilihat dalam grafik hubungan pada gambar 8.

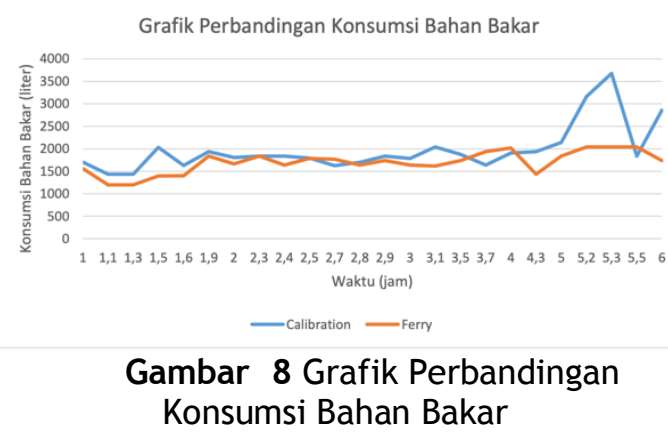

Dari grafik gambar 8, secara umum dapat di lihat terjadi perbedaan antara konsumsi bahan bakar saat terbang kalibrasi yang dapat di lihat dari grafik garis berwarna biru dengan interval waktu yang sama dengan saat melakukan terbang ferry yang diberi warna orange.

Pada interval waktu ke 1,9 kedua penerbangan mengalami nilai yang mendekati yaitu penerbangan ferry menghabiskan 1838 liter sedangkan kalibrasi 1938 liter. Namun fluktuasi terbang penerbangan kalibrasi terlihat lebih aktif dalam konsumsi bahan bakar pesawat. 
Hal ini dapat di pengaruhi oleh kecenderungan menggunakan manuver dalam prosesnya. Fluktuasi terbang dalam grafik tersebut adalah perbedaan konsumsi bahan bakar yang dapat dilihat signifikan. Naik dan turunnya konsumsi bahan bakar pada penerbangan kalibrasi lebih sering terjadi di bandingkan saat terbang ferry yang cenderung memiliki grafik terbang yang landai. Hal tersebut juga di setujui koresponden dalam pendataan kuesioner yang di lakukan terhadap koresponden pemegang lisensi pesawat dimaksud.

\section{SIMPULAN}

Simpulan hasil analisa yang telah dilakukan adalah terdapat perbedaan antara konsumsi bahan bakar saat melakukan kalibrasi dengan saat melakukan ferry dianalisis dengan aplikasi SPSS metode ANOVA menunjukkan nilai Sig. 0,022 atau kurang dari 0,05 sehingga hipotesa $\mathrm{Ha}$ tentang terdapat perbedaan antara konsumsi bahan bakar saat melakukan ferry dan kalibrasi, data ini juga di tunjukkan pada uji t-test dengan nilai Sig (2-tailed) menunjukkan nilai 0,022 sehingga hipotesa terdapat perbedaan konsumsi bahan bakar saat melakukan ferry dan kalibrasi dapat di terima.

Perbedaan paling signifikan dapat dilihat pada grafik dengan interval waktu 5,3 jam penerbangan ferry menghabiskan 2040 liter sedangkan kalibrasi menghabiskan 3676 liter.

Berdasarkan uji yang telah di lakukan, perlu dilakukan upaya untuk memaksimalkan konsumsi bahan bakar dengan mengatur jadwal penerbangan antara ferry dan kalibrasi pesawat udara. Jadwal yang teratur dengan menyeling terbang kalibrasi dan ferry secara bergantian akan membuat jadwal inspeksi rutin setiap pesawat menjadi tepat waktu termasukpenggantian komponen yang di perlukan untuk kesehatan pesawat dan agar pesawat tetap di nyatakan laik udara sesuai dengan peraturan Indonesian Civil Aviation Safety Regulation.

\section{UCAPAN TERIMA KASIH}

Terima kasih kepada Balai Besar Kalibrasi Fasilitas Penerbangan yang telah memberikan fasilitas untuk mendapatkan data-data dalam penelitian ini.

\section{DAFTAR PUSTAKA}

Fatonah, F. 2014. Metode Pengukuran Peralatan Lokalizer di Bandar Udara', Jurnal Perhubungan Udara Warta Ardhia, 40 (3), pp. 173-188.

Federal Aviation Administration. 2012 Aviation Maintenance Technician Handbook Powerplant Volume 2. Vol. 2. New Castle, United States: Aviation Supplies \& Academics Inc.

Mora, Minda dan Yusmar, T. 2014. Pengaruh Kepadatan Lalu Lintas Penerbangan Pada Saat Taxi Out Terhadap Konsumsi Bahan Bakar Pesawat Udara (Studi Kasus: Bandar Udara Internasional Soekarno Hatta). Jurnal Perhubungan Udara Warta Ardhia, 40(4), pp. 215-222.

Samsudin, R. 2010. Kalibrasi Navigasi Penerbangan dalam Mengantisipasi Keselamatan Penerbangan. Jurnal Penelitian Perhubungan Udara, 36(3), pp. 262-277.

Sujarweni, V. W. 2015. SPSS untuk penelitian. Edited by Florent. Yogyakarta: Pustaka Baru Press.

Zulaichah. 2014. Pengaruh Fasilitas Bandar Udara Terhadap Kinerja Ketepatan Waktu Maskapai Penerbangan', Jurnal Perhubungan Udara Warta Ardhia, 40(4), pp. 223-234. 